\title{
Journal updates from the managing editor
}

\author{
Lindsay MacMurray ${ }^{1}$ (iD
}

Received: 11 March 2017 / Accepted: 14 March 2017 /Published online: 8 April 2017

(C) The International Urogynecological Association 2017

The International Urogynecology Journal would not exist without the efforts and talents of all who contribute to its content. The authors, editors, and reviewers who create, review, and edit this content bring researchers and practicing urogynecologists to the journal and provide a platform for some of the best research and clinical guidance in urogynecology. A journal needs more than good content to thrive. People are often surprised to learn how much work is necessary behind the scenes to create our final product - both individual articles and full monthly issues. Since 2014, I have been the Editorial Assistant for the IUJ-one on a team of many who make certain that the journal runs smoothly and that the final product is a high-quality journal for high-quality science.

In early 2017, I took on a new role at the IUJ as Managing Editor. Just as I did as previously, I will continue to provide administrative support for the $I U J$ and ensure that the day-today operations run smoothly and that peer review is timely. Now, as the Managing Editor, I will also be working with the Editors to provide tools and support to authors, reviewers, and our readership and thus ensure that the journal continues to be the premier research outlet for practicing urogynecologists across the globe. While the Editors-in-Chief and Editors will ensure that the journal continues to publish high-quality, cutting-edge science, I, along with our publisher, will focus on strategic management in the publishing sphere by introducing author resources and publishing tools that reflect publishing trends and industry best practices. Here are a few initiatives taking place that we here at the IUJ are excited to share!

Lindsay MacMurray

iujeditorialoffice@gmail.com

1 International Urogynecology Journal, New York, NY, USA
Article template We've recently introduced an article template that authors can download from the journal's website (http://www.springer.com/medicine/gynecology/journal/192). This template outlines the journal's preferred manuscript structure for original research articles and provides instructions to ensure that submissions adheres to journal guidelines and presents research in a clear, organized format when it goes out for peer review. Our hope is that both new and experienced authors will benefit from downloading the template and following the instructions before submitting to the journal.

Social media The IUJ has a new Twitter account, and we have revived our Facebook account. I encourage to you follow us at https://twitter.com/IUJ_BlueJournal, and like us on Facebook at https://www.facebook.com/IUJBlueJournal! We will be sharing articles and posting information relevant to the journal, so please check us out and engage with fellow researchers through our online community.

Altmetric As readers may have noticed, some IUJ articles now have a "Shares" icon on the individual article page that links to an Altmetric page. Altmetric is a way of measuring the impact of an article on social media. Clicking on this link brings readers to the individual article's Altmetric page where they will see a distinct rainbow-colored Altmetric badge and information on the online attention the article has received. Here, readers can browse original mentions and shares associated with an article [1]. I encourage authors and readers to explore this feature and share IUJ articles on various social media platforms. If you wish to share an article on social media, simply go to the "Share Article" dropdown menu on an individual article page and select the social media outlet where you would like to share the article. Let's get the word out on all of the great research we are publishing! 
ORCID IDs The IUJ encourages authors to obtain an Open Researcher and Contributor ID (ORCID) and use it when submitting to the journal. For those who may be unfamiliar, ORCID is a nonprofit organization that addresses the name ambiguity problem in scholarly publishing by providing a way to uniquely identify researchers and connect them to their work [2]. An ORCID iD is a free, unique identification number assigned to authors and researchers and only takes $30 \mathrm{sec}-$ onds to create by clicking the link for the Editorial Manager homepage. The iD allows your work to be distinguished from that of authors with the same name, links together your entire published research portfolio, integrates into multiple manuscript/grant submission software platforms, and ensures that your recent and earlier work is recognized. As of February 2017, ORCID had issued over 3 million iDs [3]. When you submit to the IUJ, you have the option of submitting via your ORCID iD. If accepted for publication, your manuscript is automatically entered into the ORCID iD database and a green icon (like the one next to my name) will appear next to your name on the published article. Use of an ORCID iD is not required for submission to the IUJ, but authors are encouraged to register for one.

In conclusion, I am excited about the many changes we are bringing to bear on the journal and my new role as Managing Editor. I can be reached at iujeditorialoffice@gmail.com. I look forward to hearing from you!

\section{Compliance with ethical standards}

Conflicts of interest None.

\section{References}

1. Altmetric. Altmetric badges. Available at https://www.altmetric.com/ products/altmetric-badges. Accessed 5 March 2017.

2. ORCID. What is ORCID. Available at https://orcid.org/about/whatis-orcid/mission. Accessed 5 March 2017.

3. ORCID. Number of ORCID IDs. Available at http://support.orcid. org/knowledgebase/articles/150557-number-of-orcid-ids. Accessed 6 March 2017. 